\title{
NUMERICAL PREDICTION OF THE EFFECTS OF LONGITUDINAL CRACK-LIKE LAMINATIONS ON THE TENSILE PROPERTIES OF WIRES
}

\author{
Kazeem K. ADEWOLE \\ School of Chemical Engineering and Advanced Materials, Newcastle University, \\ Newcastle upon Tyne, United Kingdom
}

Received 11 May 2013; accepted 30 Jul 2013

\begin{abstract}
Carbon steel wires used for civil engineering applications may contain laminations. In the published literature, lamination was modelled as a separation between two faces with a finite distance. This technique is not suitable for modelling the line-type/crack-like laminations that may be present in the wires. In this paper, the effects of longitudinal line-type laminations on the tensile properties of carbon steel wires were investigated using Finite element (FE) analysis. Laminations were modelled as seams which truly simulate the line-type/crack-like laminations that have been reported to be instrumental to the failure of pre-stressing wires. FE analysis revealed that laminations do not significantly reduce the yield and ultimate loads of the wires. However, laminations cause a significant reduction in the displacement at fracture of the wires and the reduction is proportional to the length of the laminations. Consequently, the presence of laminations reduces the ductility of the wires, which reduces the ability of the wires to withstand overload the wires may experience in service without causing a catastrophic failure of structures where wires provide the required reinforcement.
\end{abstract}

Keywords: displacement at fracture, ductility, finite element analysis, laminations, tensile properties, wires.

\section{Introduction}

The presence of laminations in carbon steel wires (usually $2.5 \mathrm{~mm}$ to $8 \mathrm{~mm}$ in size) and bars (usually $10 \mathrm{~mm}$ to $32 \mathrm{~mm}$ ) used for the construction of pre-stressed concrete structures, flexible pipes, suspended and cable-stayed bridges and for other applications in civil and structural engineering is associated with the impurity or defects in the steel and the rolling and/or drawing manufacturing processes of the wires/bars. A lamination is an elongated line-type defect or a long crack that constitute a material separation or discontinuity (Peet, Wilde 2001) and is usually parallel to the surface of metal products produced through rolling or drawing process (Smith et al. 1957). Laminations are normally invisible at the surface and are revealed during pressing or drawing of the metal products (e.g. wires/bars) (Smith et al. 1957). Laminations result from the elongation of cylindrical cavities in the parent ingot during rolling or drawing process (Smith et al. 1957) or from slag and mould powder entrapment during the steel making or casting process (Moir, Preston 2002). Lamination may also be caused by non-metallic inclusions $(\mathrm{MnS})$ or by alloy segregation that is made directional by working the material (Escoe 2006). There is the need to understand the effect(s) of laminations on the tensile properties of wires/bars for civil engineering applications as the catastrophic rupture of pre-stressed concrete pipes has been attributed to the presence of long pre-service long longitudinal cracks or laminations in the pre-stressing wires used for the construction of the failed pre-stressed concrete pipes by the United States Bureau of Reclamation (1994). The United States Bureau of Reclamation (1994) reported that the long pre-service longitudinal cracks were very straight for great lengths and were several feet in length. The cracks can thus be described as laminations.

Most literature on laminations such as that of Peet and Wilde (2001), and Fazzini et al. (2005) are on the effects of laminations on the integrity of pipelines. Typical laminations that have been detected in pipelines by transversal magnetic flow and UltraScan wall measurement inline internal inspection tools are between less than $1 \mathrm{~mm}$ and up to $4.2 \mathrm{~mm}$ in the pipeline's radial or through thickness direction (i.e. the thickness of the lamination), with widths between 10 and $200 \mathrm{~mm}$, and total lengths that are significantly larger than the width and the dimension in the through thickness direction (Fazzini et al. 2005). Fazzini et al. (2005) modelled these laminations as a separation between two faces with a finite interval between the two faces. While this modelling technique is suitable for modelling the laminations found in pipelines (with finite thickness of $1 \mathrm{~mm}$ to $4.2 \mathrm{~mm}$ as presented earlier), it is not suitable for modelling the line-type or crack-like laminations (long longitudinal cracks) such as those that were observed by the United States Bureau of Reclamation

Corresponding author: Kazeem K. Adewole

E-mail: kkadewole@yahoo.com 
(1994) in the failed pre-stressing wires used for the construction of the ruptured pre-stressed concrete pipes that may be present in steel wires for civil engineering applications. Also, the experimental investigation of the effects of laminations on the integrity of pipelines conducted by Peet and Wilde (2001), were conducted on specimens with pre-service or existing lamination (i.e. the laminations were not machined into the specimens). This could be due to the fact that it is not experimentally possible to machine laminations, especially, the line-type or cracklike laminations such as the laminations in the ruptured pipe pre-stressing wire reported by the United States Bureau of Reclamation (1994). Consequently, there is the need for an appropriate modelling technique that truly simulates the line-type or crack-like laminations observed in wires used for civil engineering applications.

This work presents the investigation of the effects of longitudinal mid-width laminations that are parallel to the wires' drawing or rolling direction on the tensile properties of typical carbon steel wires for civil engineering applications. The investigation involves laboratory tensile testing and FE simulations of the tensile testing of lamination-free wires and the finite element simulation of the tensile testing of wires with laminations. The three dimensional FE simulations were conducted with the isotropic elastic-plastic model combined with the micromechanical-based phenomenological shear failure fracture mechanics model in-built in Abaqus finite element code. Details of the isotropic elastic-plastic model and the phenomenological shear fracture mechanic model and the modelling parameters for the two models can be found in the work of Adewole and Bull (2013).

The simulation was conducted with the micromechanical-based phenomenological shear fracture mechanics model because as stated by Mahmoud (2007), Toribio and Valiente (2004, 2006), it is impossible to employ the classical fracture mechanics concept to predict the tensile and fracture properties of cracked wires as standardised fracture mechanics specimens could not be manufactured from the wires due to the size of wires. This explains why the recent research on the determination of the fracture properties and fracture mechanism of cracked wires, such as the research conducted by Mahmoud (2007) on bridge cable wires, and by Toribio and Valiente (2004), Toribio and Valiente (2006) on concrete pre-stressing wires employed non-standardised fracture mechanics specimens for their analysis.

\section{Experimental}

The details of the laboratory and numerical experiments for the tensile testing of the lamination-free wire specimen and the wires specimens with lamination are as follows.

\subsection{Laboratory tensile testing}

Twelve full size specimens of $12 \times 5 \mathrm{~mm}$ and $12 \times 7 \mathrm{~mm}$ lamination-free wires shown in Figure 1(a) were tested in accordance with ASTM E8M:2009 (2009) specifications using an Instron universal testing machine (IX 4505 ) with a static capacity of $\pm 100 \mathrm{kN}$. The tensile specimens of the wire were held with wedge grips and the laboratory tensile tests were conducted on $170 \mathrm{~mm}$ long, $50 \mathrm{~mm}$ gauge length wire specimens at an ambient temperature of $20{ }^{\circ} \mathrm{C}$, a relative humidity of $38 \%$ and a cross head speed of $5 \mathrm{~mm} / \mathrm{min}$. The displacement was measured with an Instron 2630-112 clip-on strain gauge extensometer with a $50 \mathrm{~mm}$ gauge length which ensured that only the $50 \mathrm{~mm}$ gauge length elongation was measured.

\subsection{FE element tensile testing simulation}

Taking an advantage of the symmetry of the wire specimen, the three dimensional FE simulations of the tensile testing of the lamination-free wire specimens and the wire specimens with mid-width (width of the wire specimen model in the Y-axis direction) laminations were conducted with models of the wire specimens with half the thickness (thickness of the wire specimen model in the $\mathrm{Z}$-axis direction) of the wire as shown in Figure 1(b). The simulations of the tensile testing of the laminationfree wires specimen and the wire specimens with midwidth lamination were conducted with the same material input data obtained from the laboratory tensile testing of the lamination-free wire specimens. However, for the simulation of the tensile testing of the lamination-free wire, the mid-width partition which is not visible in the meshed wire model in Figure 1(b) and which is as shown in the wireframe image in Figure 1(c) was modelled as

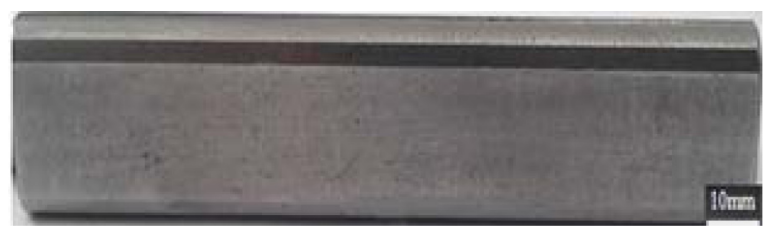

(a) Experimental wire specimen

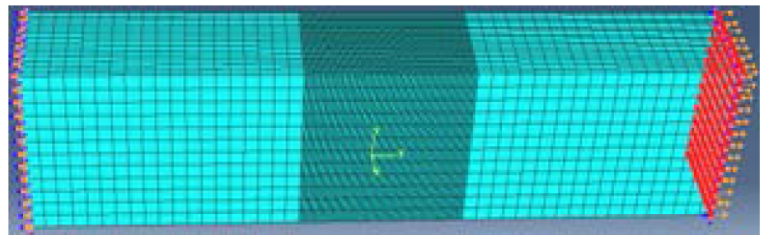

(b) FE model of wire specimen

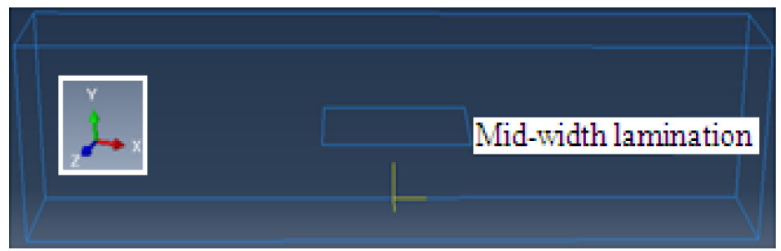

(c) Wireframe model of wire specimen with mid-width lamination

Fig. 1. Laboratory specimen and FE models of wire specimen with and without laminations 
ordinary partitions, whereas, for the simulations of the tensile testing of the wire specimens with laminations, the mid-width partition was modelled a seam to simulate the line-type or crack-like laminations. A seam in Abaqus is used to model cracks and faces that are originally closed but open during analyses.

The elastic-plastic response modelling parameters employed for the FE simulations are the density, Young's modulus, Poisson's ratio, and the true plastic stress and strain from the yield stress to the ultimate tensile stress of the wire. The values for these parameters are not specified in this paper for confidentiality (Non-disclosure agreement between the wire supplier and Newcastle University). The shear damage and fracture modelling parameters employed for the FE simulations are fracture strain of 0.3451 , shear stress ratio of 12.5 , strain rate of $0.000125 \mathrm{~s}^{-1}$ and a material parameter $\mathrm{K}_{\mathrm{s}}$ of 0.3 . These are the calibrated shear damage and fracture modelling parameters established by Adewole and Bull (2013) as the appropriate shear damage and fracture modelling parameters for the wires considered in this work through a phenomenological curve fitting procedure. Details of the phenomenological curve fitting procedure are available in the work of Adewole and Bull (2013).

The outer and the middle regions of the models of both the lamination-free wire specimen and the wire specimen with laminations were meshed with $1 \mathrm{mmx} 1 \mathrm{~m}$ $\mathrm{mx} 1 \mathrm{~mm}$ and $0.1 \times 0.1 \times 1 \mathrm{~mm}$ C3D8R elements respectively as shown in Figure 1(b). $0.1 \times 0.1 \times 1 \mathrm{~mm}$ element size was established through mesh convergence study as the optimum mesh size required for an accurately prediction of the tensile and fracture behaviours of both the lamination free wire specimen and the wire specimen with laminations. Figure 1(b) shows the boundary condition employed for the tensile testing simulations. It consists of a completely fixed boundary condition at the left hand end of the model and a boundary condition which allows only horizontal displacement in the longitudinal (X-axis) direction of the wire specimens. During the tensile testing simulations, longitudinal displacements were applied to the right hand end of the specimens as shown by the arrows in Figure 1(b). FE tensile testing simulations were employed to investigate the effects of longitudinal laminations with lengths from $1 \mathrm{~mm}$ to $10 \mathrm{~mm}$ on the tensile properties of the wires.

\section{Results}

For confidentiality (non-disclosure agreement with the wire's supplier), all the force-displacement curves presented in this paper are normalised with the experimental ultimate load and displacement at fracture of the lamination-free wire. The FE predicted deformed shapes for the $12 \times 7 \mathrm{~mm}$ lamination-free wire specimens and the $12 \times 7 \mathrm{~mm}$ wire specimens with mid-width lamination throughout the uniform elastic and plastic deformations up to the ultimate load point are the same and only the deformed shapes at the ultimate load point at which necking commenced are presented in Figure 2. The FE predicted fully necked wire specimens with and without laminations are shown in Figure 3. The fractured experimental specimens and the FE predicted fractured models of the wire specimens with and without mid-width laminations are shown in Figures 4 and 5 respectively. Similar deformed shapes during the uniform elastic and plastic deformations, fully necked specimens and fractured shapes were predicted for the two wires wire sizes.

A small variation of a few percent (with standard deviations of approximately $0.32,0.34$ and 0.42 in the yield, ultimate and the displacement at fracture of the wires) was observed in the test results among different samples of the two wire sizes considered. The normalised force displacement-curves from the lamination-free samples of the as-received $12 \times 5 \mathrm{~mm}$ and $12 \times 7 \mathrm{~mm}$ wire specimens with properties closest to the mean are presented in Figure 6. The FE predicted force-displacement curves for the $12 \times 7 \mathrm{~mm}$ lamination-free wire specimen and that of the $12 \times 7 \mathrm{~mm}$ wire specimens with mid-width

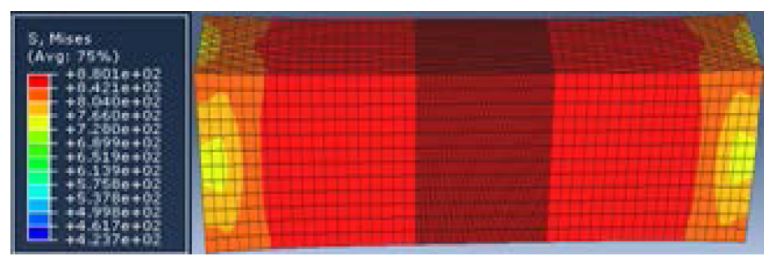

(a) Lamination free wire specimen

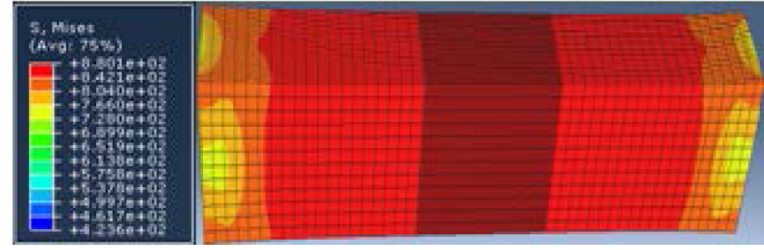

(b) Wire specimen with mid-width lamination

Fig. 2. Deformed shapes of models of wire specimens with and without laminations at ultimate load point prior to necking

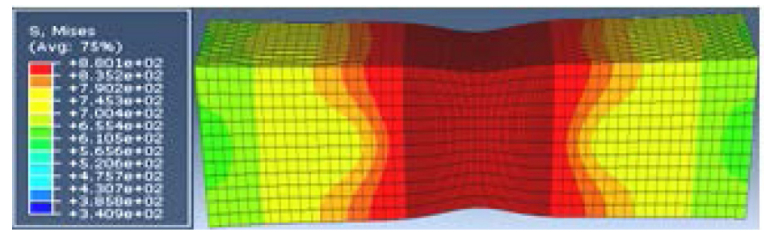

(a) Lamination-free wire specimen

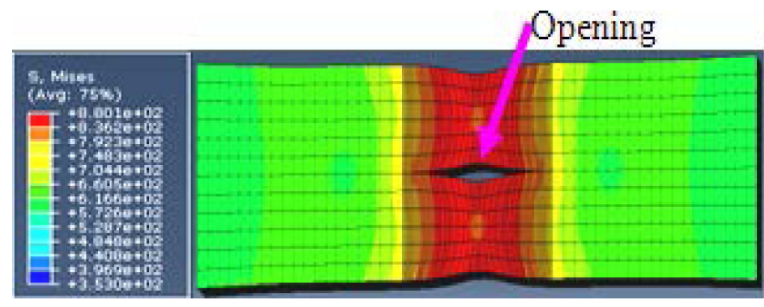

(b) Wire specimen with mid-width lamination

Fig. 3. FE predicted fully necked models of wire specimens with and without lamination 


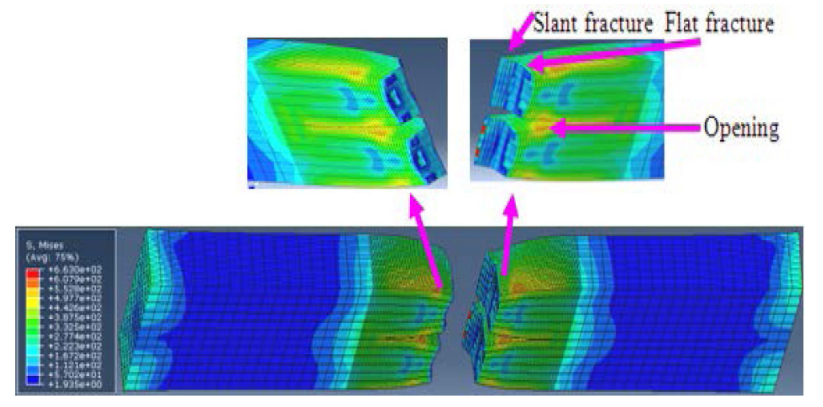

(a) FE predicted fractured model of wire specimen with lamination

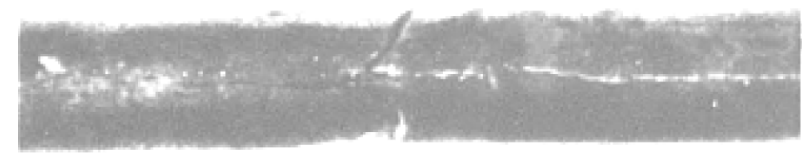

(b) Fractured experimental specimen of wire with lamination, 3X (United States Bureau of Reclamation, 1994)

Fig. 4. Experimental and FE predicted fractured specimens of wire with lamination

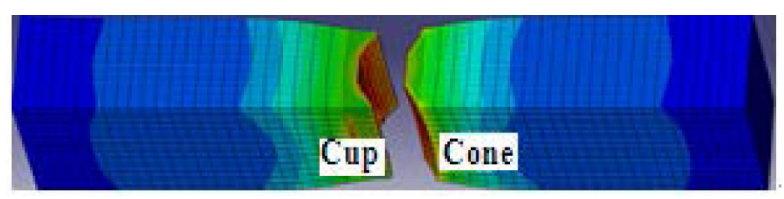

(a) FE predicted fractured model of wire specimen without lamination

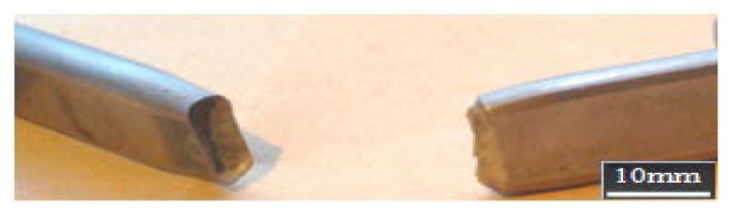

$12 \times 5 \mathrm{~mm}$

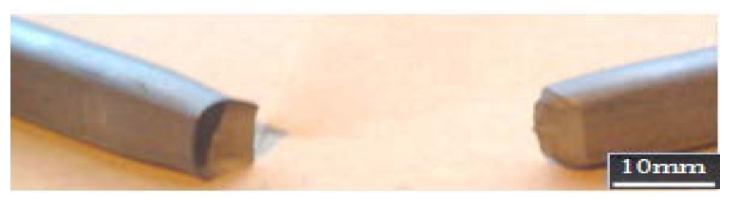

$12 \times 7 \mathrm{~mm}$

(b) Fractured experimental specimen of wire without lamination

Fig. 5. Experimental and FE predicted fractured wire specimens without lamination

laminations are shown in Figure 7. The variations of the yield load, the ultimate load and the displacement at fracture with varying mid-width and near-surface lamination lengths are shown in Figures 8, 9 and 10 respectively.

\section{Discussion}

The good agreements between the lamination-free wire specimens' experimental and FE predicted

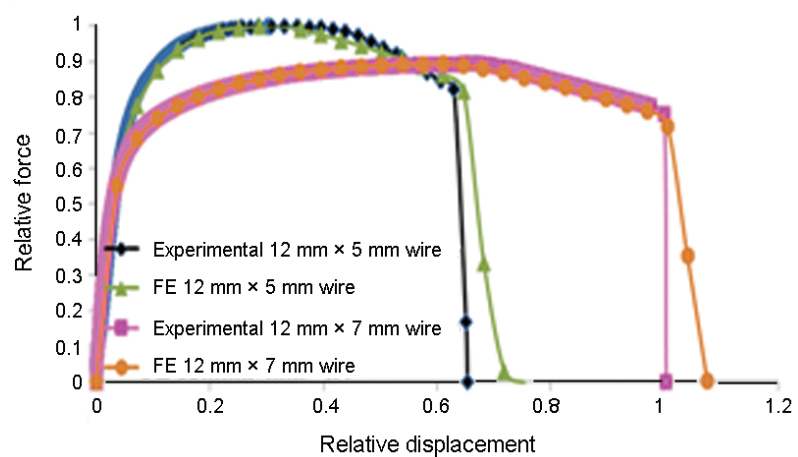

Fig. 6. Experimental and FE predicted force-displacement curves for lamination-free wires

force-displacement curves shown in Figure 6 and the experimental and FE predicted cup and cone fracture shape (with flat fracture at the center and slant fracture at the outer edges of the specimen) shown in Figures 4(a) and 5, demonstrate the accuracy of the FE simulation in predicting the wire's tensile and fracture behaviours. A complete cup and cone fracture is formed if the predicted fractured half models of the wire specimens in Figure 4 are mirrored about the axis of symmetry (Z-axis). The accuracy of the finite element simulations of the tensile testing of the wires specimens with laminations could not be validated with experiments, as it was not possible to machine long longitudinal mid-width line-type/ crack-like laminations that are parallel to the length of the wire specimens and cut through the width of the wire specimens as modelled in the FE simulations. However, the ability of the FE simulations to predict insignificant reductions in the ultimate tensile load of the wire with laminations (Fig. 7), which agrees with what was experimentally observed by the United States Bureau of Reclamation (1994) confirms the accuracy of the simulation. Also, the ability of the FE simulations to predict a cup and cone fracture shape with an opening at the center of the cup and cone fracture which extends along the length of the wire as shown in Figure 4(a) for the wires specimen with laminations which also agrees with the fracture shape of wires specimens with preservice longitudinal line-type laminations fractured by experimental tensile testing obtained from United States Bureau of Reclamation (1994) which equally exhibit a cup and cone fracture with an opening at the center of the cup and cone fracture which extends along the length of the wire further confirms the accuracy of the simulation.

In Figure 6, the normalised ultimate tensile load of the $12 \times 5 \mathrm{~mm}$ wire is higher than that of the $12 \times 7 \mathrm{~mm}$ wire, while the normalised displacement at fracture of $12 \times 5 \mathrm{~mm}$ wire is less than that of the $12 \times 7 \mathrm{~mm}$ wires because the $12 \times 5 \mathrm{~mm}$ was manufactured from the $12 \times 7 \mathrm{~mm}$ wires. The drawing process increased the ultimate tensile load of the $12 \times 5 \mathrm{~mm}$ wire and reduced its displacement at fracture due to work hardening and the reduction in the amount of available plastic deformation respectively. Figure 2 shows that there is no significant differences in 


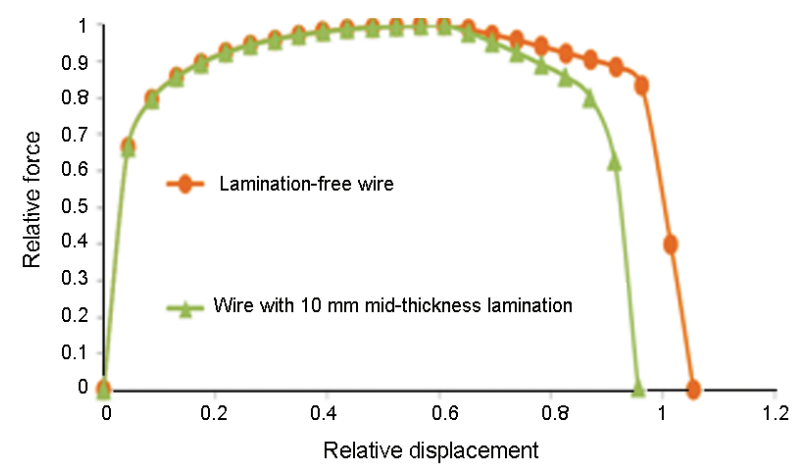

Fig. 7. FE predicted force-displacement curves for the wire with and without laminations

the FE predicted deformed shapes and the Misses stress distributions in the lamination-free wire specimens and the wire specimens with laminations at the ultimate load point where necking commenced. Conversely, there are significant differences in the FE predicted fully necked and the fractured lamination-free wire specimens, both of which exhibit no opening as shown in Figures 3(a) and 5(a) respectively, and the fully necked and fractured wire specimens with mid-width laminations with openings as shown in Figures 3(b) and 4(b) respectively. In the assembled fractured specimen of the wire specimen with lamination in Figure 4(b), the left hand side fractured piece and the right hand side fractured piece respectively represent the cup section and the cone sections of the cup and cone fracture exhibited by the fractured specimen of the wire specimen with lamination. There is no opening in the fully necked and the fractured lamination-free wire specimen because during necking, the entire cross section of the lamination-free wire specimen necks down as a single unit as shown in Figure 3(a). Openings exist in the wire specimens with laminations because the presence of the laminations (material separations) divides the wire specimens into two ligaments along the wire's thickness with each ligament necking separately, thereby creating an opening between the two ligaments as each ligament shrinks in opposite vertical directions as shown in Figure 3(b). The opening which occurred during necking is also visible in the magnified experimental fractured wire specimen with lamination presented in Figure 4(b).

Figures 8,9 and 10 show the variations of the yield load, the ultimate load and the displacement at fracture of the wire with lamination lengths and can thus serve as design curves that could be used to estimate the tensile properties of wires with laminations of $1 \mathrm{~mm}$ to $10 \mathrm{~mm}$ lengths. Figures 8, 9 and 10 show that the presence of mid-width laminations reduces the yield load, the ultimate load and the displacement at fracture of the wires and the reductions are proportional to the length of the laminations. Figure 10 shows that the rate of reduction in the displacement at fracture of the wire with lamination length greater than $4 \mathrm{~mm}$ is small compared to the rate of reduction in the displacement at fracture of the wire with lamination lengths less than $4 \mathrm{~mm}$. Figures 8, 9 and 10 also show that the mid-width lamination causes 0.02 to $0.11 \%, 0.001$ to $0.06 \%$ and 3.76 to $13.04 \%$ reductions in the yield load, the ultimate load and the displacement at fracture of the wire respectively. This result indicates that the presence of lamination has no significant effects (i.e. no significant reductions) on the yield and ultimate loads of the wire which agrees with what was reported by the United States Bureau of Reclamation (1994). This result also indicates that the presence of lamination significantly reduced the displacement at fracture and consequently the ductility of the wires, which also agrees with what was reported by the United States Bureau of Reclamation (1994). This is due to the fact that as revealed by the FE simulations, the presence of laminations has no significant or noticeable effect on the wire's uniform elastic and plastic deformations (Fig. 2); mises stress distribution (Fig. 2) and the force-displacement response (Fig. 7) of the wire up to the ultimate load point.

The presence of laminations only has significant effects on the localised non-uniform extension and deformation of the wire during necking (noticeably, the opening in the necked wire with laminations), the post necking force-displacement response of the wire (noticeably, the reduced displacement at fracture of the wire with laminations), and the fracture shape (cup and cone fracture with an opening at the center of the cup and cone fracture which extends along the length of the wire as shown in Fig. 4b) of wire specimens with laminations.

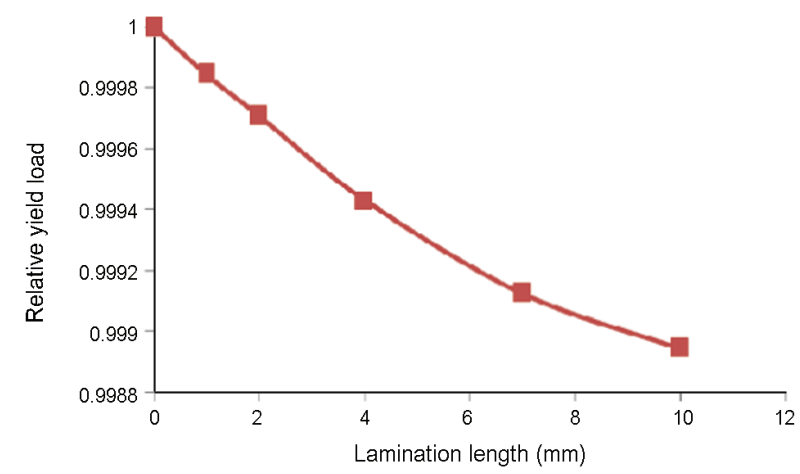

Fig. 8. Variation of yield load with lamination length

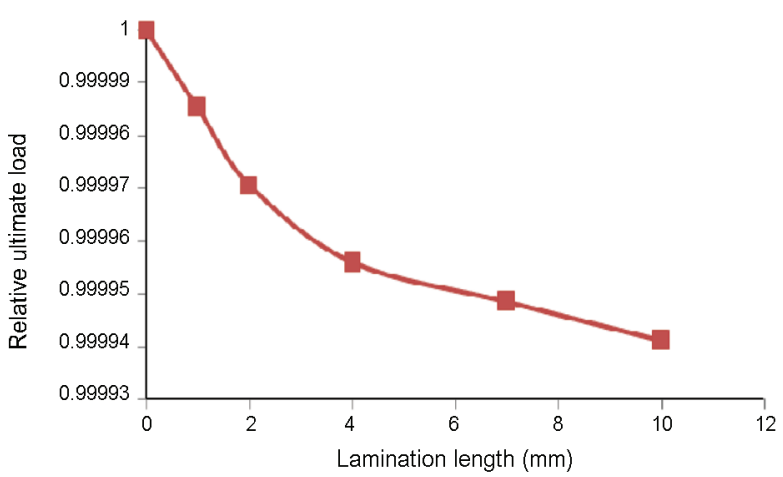

Fig. 9. Variation of ultimate load with lamination length 


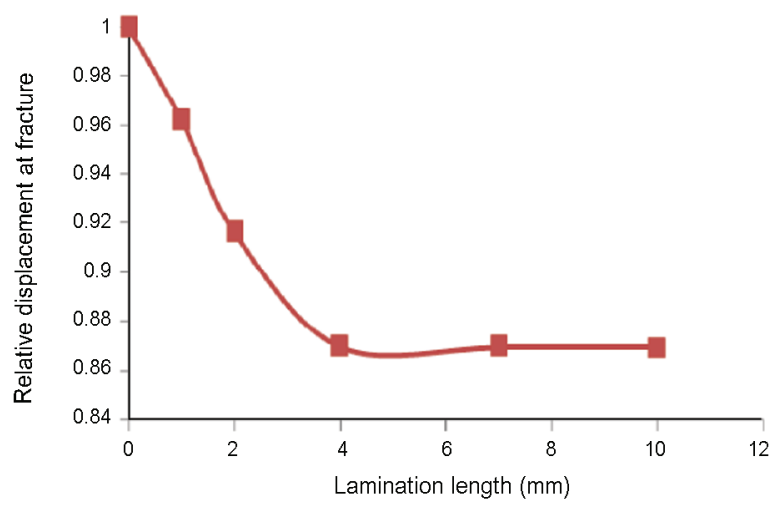

Fig. 10. Variation of displacement at fracture with lamination length

Consequently, the high rate of reduction in the displacement at fracture of the wires with lamination lengths less than $4 \mathrm{~mm}$ compared to the wires with lamination lengths greater than $4 \mathrm{~mm}$ could be attributed to the fact that the highest reductions in the lateral and transverse dimensions of the wire during necking which determines the extension of the wire between the commencement of necking to the fraction initiation point and consequently determines the displacement at fracture of the wire significantly occurs within the middle $4 \mathrm{~mm}$ length of the wire specimen as shown in Figure 3(b). Thus it can be said that the low rate of reduction in the displacement at fracture of the wire with lamination length greater than $4 \mathrm{~mm}$ is due to the low lateral and transverse reductions in the dimensions of the wire outside the middle $4 \mathrm{~mm}$ length of the wire during necking.

The significant reduction in the displacement at fracture of the wire and consequently, the reduction in the ductility of the wire reduce the wires' ability to withstand overloads such as the surges experienced by the ruptured pres-stressed concrete pipe during valve closings without a catastrophic failure. The reduction in the ductility of the pre-stressing wires used for the construction of the ruptured pre-stressed concrete pipe by the presence of pre-service laminations could be responsible for the wires inability to withstand surges experienced by the ruptured pres-stressed concrete pipe during valve closings and led to the catastrophic rupture of the pipe. Although for practical engineering design purposes, emphasis are placed on the yield and the ultimate loads of the wires which are not significantly affected by laminations, this result highlights the need to take into consideration the reduction in the ductility of wires by laminations during design so as to ensure that the wires have sufficient ductility to withstand overloads without catastrophic failure.

The reduction in the displacement at fracture of the wire specimens with laminations is due to the reduced necking (lower lateral and transverse contractions) exhibited by the wire specimens with laminations shown in Figure 3(b) when compared with the substantial necking exhibited by the lamination-free wire speci- men shown in Figure 3(a). The reduced necking of the wire specimens with laminations predicted by the FE simulation agrees with the reduced reduction in area (reduced necking) exhibited by the failed pre-stressing wire with pre-service laminations reported by the United States Bureau of Reclamation (1994). The reduced necking which is due to the lower lateral and transverse contractions of the wire specimens with laminations reduces the elongation or the displacement to fracture of the wire specimens because the longitudinal elongation of the wire is proportional to the lateral and transverse contractions of the wire.

\section{Conclusions}

This study presents the finite element simulation techniques employed for the investigation of the effects of laminations on the tensile properties of a typical carbon steel wire for civil engineering applications with and without laminations. It is demonstrated that the finite element simulation techniques employed in this work is able to predict the tensile and fracture behaviours of the typical carbon steel wire with laminations considered in this work. This study also presents design curves that could be used to estimate the tensile properties of wires with laminations of $1 \mathrm{~mm}$ to $10 \mathrm{~mm}$ length. The investigation revealed that the presence of mid-width laminations reduces the yield load, the ultimate load and the displacement at fracture of the wires and the reductions are proportional to the length of the laminations. The investigation also revealed that the presence of laminations with $1 \mathrm{~mm}$ to $10 \mathrm{~mm}$ in length considered in this work has no significant effects on the yield and the ultimate loads of the wire as the presence of laminations has no significant or noticeable effects on the wires' uniform elastic and plastic deformations up to the ultimate load point where necking begins. However, the presence of laminations with $1 \mathrm{~mm}$ to $10 \mathrm{~mm}$ in length causes significant reductions of 3.76 to $13.04 \%$ in the displacement at fracture of the wire due to reduced necking exhibited by the wire specimens with laminations.

The significant reduction in the displacement at fracture of the wire and consequently, the reduction in the ductility of the wire by laminations reduce the wires' ability to withstand overloads without a catastrophic failure. This result indicates that the presence of longitudinal laminations in wires used for civil engineering application threatens the structural integrity of the wires and consequently threatens the structural integrity of wire-reinforced structures. Thus, it can be inferred that the significant reduction in the displacement at fracture and consequently, the reduction in the ductility of the prestressing wires used for the construction of the ruptured pre-stressed concrete pipe by pre-service laminations reduce the wires' ability to withstand overloads without a catastrophic failure and could be the reason for the catastrophic rupture of the pre-stressed concrete pipe 
reported by the United States Bureau of Reclamation (1994), which experienced surges (overloads) during valve closings. This work thus provides a numerical prediction/analysis of the tensile behaviour of wires with laminations and provides a better understanding of the possible reasons for the failure of pre-stressing wires with pre-service longitudinal cracks or laminations such as the one used for the construction of the pre-stressed concrete pipes that ruptured catastrophically as reported by United States Bureau of Reclamation (1994). This study also highlights the need to take into consideration the reduction in the ductility of wires by laminations during design so as to ensure that the wires have sufficient ductility to withstand overloads during service without causing a catastrophic failure of wire-reinforced structures.

\section{References}

Adewole, K. K.; Bull, S. J. 2013. Prediction of the fracture performance of defect-free steel bars for civil engineering applications using finite element simulation, Construction and Building Materials 41: 9-14. http://dx.doi.org/10.1016/j.conbuildmat.2012.11.089

ASTM E8M. 2009. Standard Test Method for Tension Testing of Metallic Materials. American Society for Testing of Materials. USA, 2009.

Escoe, K. A. 2006. Piping and pipeline assessment guide. USA, Burlington: Gulf Professional Publishing.

Fazzini, P. G.; Cisilino, A. P.; Otegui, J. L. 2005. Experimental validation of the influence of lamination defects in electrical resistance seam welded pipelines, International Journal of Pressure Vessels and Piping 82(12): 896-904. http://dx.doi.org/10.1016/j.ijpvp.2005.07.006

Mahmoud, K. M. 2007. Fracture strength for a high strength steel bridge cable wire with a surface crack, Theoretical and Applied Fracture Mechanics 48(2): 152-160. http://dx.doi.org/10.1016/j.tafmec.2007.05.006

Moir, S.; Preston, J. 2002. Surface defects- evolution and behaviour from cast slab to coated strip, Journal of Materials Processing Technology 125-126(2002): 720-724. http://dx.doi.org/10.1016/S0924-0136(02)00318-7

Peet, S.; Wilde, A. 2001. Laminations-origin, detection and assessment, in Congreso Internacional de Ductos, 14-16 November 2001, Merida Yucatan, Mexico.

Smith, B. O.; Jenning, A. P. H; Grimshaw, A. G. 1957. A portable lamination detector for steel sheet, British Journal of Applied 9(5): 191-193. http://dx.doi.org/10.1088/0508-3443/9/5/305

Toribio, J.; Valiente, A. 2004. Approximate evaluation of directional toughness in heavily drawn pearlitic steels, Materials Letters 58(27-28): 3514-3517. http://dx.doi.org/10.1016/j.matlet.2004.06.040

Toribio, J.; Valiente, A. 2006. Failure analysis of cold drawn eutectoid steel wires for prestressed concrete, Engineering Failure Analysis 13(3): 301-311. http://dx.doi.org/10.1016/j.engfailanal.2005.03.003

United States Bureau of Reclamation 1994. Prestressed concrete pipe failure Jordan Aqueduct, reach 3. All U.S. Government Documents (Utah Regional Depository). Paper 284 [online], [cited 15 November 2012]. Available from Internet:

http://digitalcommons.usu.edu/govdocs/284

Kazeem K. ADEWOLE. He is holds a Bachelor's and Master's degrees in Civil Engineering and worked for the Standards organization of Nigeria as a Standards Engineer in charge of laboratory testing, standards development and quality assurance of civil engineering and building materials before going to the United Kingdom for further studies. He completed a Master's degree in Pipeline Engineering from Newcastle University and completed his $\mathrm{PhD}$ in the School of Chemical Engineering and Advanced Materials of the University of Newcastle in the United Kingdom. He presently works as a lecturer in the Civil Engineering Department of the University of Ibadan in Nigeria. 